\title{
Optimization of the Mixing Time Using Asymmetrical Arrays in Both Gas Flow and Injection Positions in a Dual-plug Ladle
}

\author{
José de Jesús VILLELA-AGUILAR, ${ }^{1)}$ José Ángel RAMOS-BANDERAS, ${ }^{1{ }^{1 *}}$ \\ Constantin Alberto HERNÁNDEZ-BOCANEGRA, ${ }^{1,2)}$ Antonio URIÓSTEGUI-HERNÁNDEZ1) and \\ Gildardo SOLORIO-DÍAZ ${ }^{3)}$
}

1) TecNM/I.T. Morelia, Tecnológico 1500 Av., Morelia, Michoacán, 58120 México.

2) CATEDRAS-CONACYT, Insurgentes Sur 1528 Av., CDMX, 03940 México.

3) UMSNH, Posgrado en Ingeniería Mecánica, F.J. Mujica Av., Morelia, Michoacán, 58040 Mexico.

(Received on November 2, 2019; accepted on December 2, 2019; J-STAGE Advance published date:

March 13, 2020)

\begin{abstract}
In this work, the multiphase mathematical simulation (steel-argon-slag-air) was used to improve the mixing time in a secondary refining ladle, which is validated with a physical scale model using dye tracer dispertion and measurement of mixing time. An experimental $3^{k-p}$ design was performed to optimize the number of cases and analyze the effect of injection gas flow arrangement. A mathematical methodology was described to determine the mixing time in a ladle with a multi-sensor system. By means of an analysis of variance, it was found that the angle of separation between plugs is the most relevant variable to reduce mixing time. It was determined that, by using a good asymmetric configuration in both gas flow and location of the porous plugs, it is possible to reduce the mixing time in a secondary steel refining ladle.
\end{abstract}

KEY WORDS: mixing time; ladle furnace; numerical model; physical modeling.

\section{Introduction}

Steel stirring with argon gas is a common practice in modern secondary refining that allows thermal and chemical homogenization in the ladle furnace. Mixing time $\left(\tau_{\text {mix }}\right)$ is defined as the time at which there is a chemical homogeneity of $95 \%$ in steel. ${ }^{1)}$ There are several physical and chemical mechanisms involved in mixing, such as molecular diffusion of alloys, turbulent diffusion caused by recirculations and convective flows promoted by steel movement. ${ }^{2)}$ Argon injection is commonly performed through porous plugs located at the bottom of the ladle, promoting the exchange of momentum from the argon bubbles of the plume. In addition, by increasing convective flow, argon injection accelerates the chemical reactions that occur between the slag layer and the steel, as well as the removal of non-metallic inclusions. Therefore, the quality of the steel has been related to the gas flow and the location of the porous plugs employed in the secondary refining. ${ }^{3)}$ However, the excessive use of gas has some drawbacks such as oxidation of steel and slag drag due to intense emulsification. ${ }^{4}$ ) Several studies have been carried out on the influence of the flow of injected gas $^{5-8)}$ and the position of the porous plugs on the mixing time. ${ }^{9-13)}$ However, in these works the same flow of argon is injected through each plug when double injection is used. Few works consider asymmetric injections either in the flow

\footnotetext{
* Corresponding author: E-mail: arblss@hotmail.com DOI: https://doi.org/10.2355/isijinternational.ISIJINT-2019-688
}

distribution ${ }^{14)}$ or in the location of the plugs. ${ }^{15)}$ On the other hand, there have been reports that correlate the mixing time with the gas flow and the slag layer. ${ }^{16-22)}$ However, there are numerous variables that affect the mixing time such as gas flow rate, number and location of porous plugs, slag layer type and thickness, ladle capacity, etc.; thus, establishing a global correlation that weighs the individual effect of each variable can be complicated. There are works ${ }^{23,24)}$ that have used an experimental design in order to reduce the cases of study. However, these studies do not consider asymmetry in the gas flow injection and in the location of porous plugs.

The aim of this work is to determine the effect of an asymmetric arrangement on the location of the porous plugs, as well as an asymmetric distribution in the gas flow by means of multiphasic mathematical modeling. A $3^{\mathrm{k}-\mathrm{p}}$ factorial design was developed to reduce the number of simulations needed and to determine the effect of each of the variables on the mixing time. The results were validated with experimental data from a 1:7 scale model of a ladle furnace.

\section{Methodology}

\subsection{Experimental Design $3^{\text {k-p 25) }}$}

In this work, the best cases employing dual porous plug to reduce the mixing times of some studies $^{5-7,11,15,26,27)}$ have been used to build the experimental design. The total argon flow was $1.0 \mathrm{Nm}^{3} \cdot \mathrm{min}^{-1}$, divided between the two injections. The representative experiments were determined using the $3^{\mathrm{k}-\mathrm{p}}$ fractional factorial design, taking 3 input vari- 
ables -gas flow, radial position and separation angle- on the response variable -mixing time- as shown in Fig. 1. Each variable has 3 levels of operation as shown in Table 1. Since the process consists of two injections, a block factorial design was selected and calculated using the Statistica ${ }^{\circledR}$ program. Each block considers different argon flow per inlet and a different radial position, the experimental matrix is shown in Table 2.

\subsection{Validation of Mixing Time}

For the validation of the numerical cases, the case 2 was selected and the mixing time was determined using a 1:7 scale physical model of a metallurgical ladle, which involves an acrylic vessel filled with water, mineral oil layer and stirred with air, as illustrated in Fig. 2(a). A sample of $35 \mathrm{~mL}$ of saturated solution $\mathrm{KCl}$ was released at the center of the oil aperture zone, at $1 \mathrm{~cm}$ below the

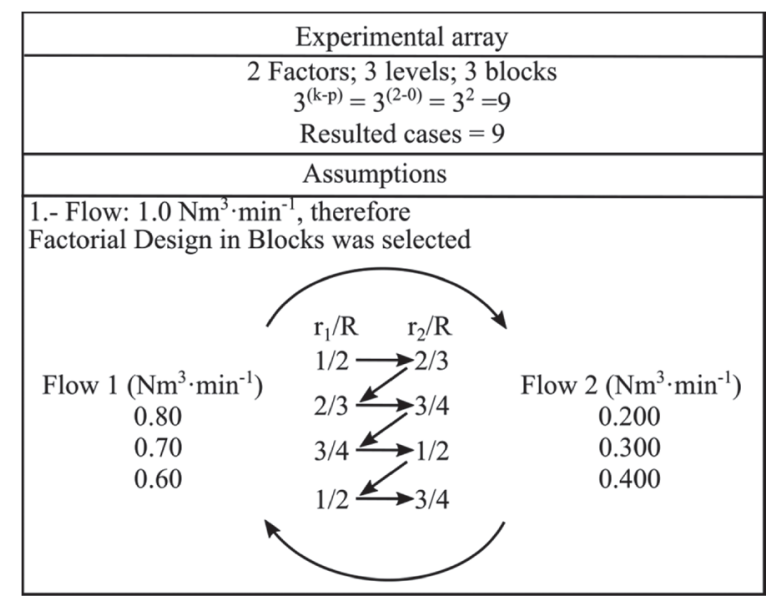

Fig. 1. Experimental design methodology. free surface. The concentration of the $\mathrm{KCl}$ in water was monitored by an Oakton ${ }^{\circledR}$ CON 110 conductivity meter with an ECCONSEN91W conductivity electrode, measurements were obtained every $5 \mathrm{~s}$, and the data were sent to a computer for processing. The sensor was placed $1 \mathrm{~cm}$ from the opposite wall to the injection as illustrated in Fig. 2(b). The test was repeated 5 times under the same conditions, to corroborate the reproducibility of the experiment. The modified Froude number (Eq. (1) $)^{28)}$ was used to determine the flows in the scale model:

$$
\left(\frac{Q_{m}}{Q_{p}}\right)^{2}=\left(\frac{\rho_{g}}{\rho_{a}}\right)\left(\frac{\rho_{w}}{\rho_{s}}\right)\left(\frac{d_{m}}{d_{p}}\right)^{4}\left(\frac{H_{m}}{H_{p}}\right)
$$

where subscripts $m$ and $p$, represent the model and the prototype, respectively; $Q$ is the volumetric flow of injected gas, $\mathrm{m}^{3} \cdot \min ^{-1} ; d$ is the diameter of the injection, $\mathrm{m} ; H$, is

Table 2. Resulted numerical cases.

\begin{tabular}{cccccc}
\hline Case & $\begin{array}{c}\text { Flow 1 } \\
\left(\mathrm{Nm}^{3} \cdot \mathrm{min}^{-1}\right)\end{array}$ & $\begin{array}{c}\text { Flow 2 } \\
\left(\mathrm{Nm}^{3} \cdot \mathrm{min}^{-1}\right)\end{array}$ & $\begin{array}{c}\text { Angle, } \\
\text { ( }\end{array}$ & $\begin{array}{c}\text { Radial } \\
\text { position 1, } \\
(\mathrm{r} / \mathrm{R})\end{array}$ & $\begin{array}{c}\text { Radial } \\
\text { position 2, } \\
(\mathrm{r} / \mathrm{R})\end{array}$ \\
\hline 1 & & & 60 & $1 / 2$ & $2 / 3$ \\
2 & 0.80 & 0.20 & 90 & $2 / 3$ & $3 / 4$ \\
3 & & & 120 & $3 / 4$ & $1 / 2$ \\
\hline 4 & & & 60 & $1 / 2$ & $2 / 3$ \\
5 & 0.70 & 0.30 & 90 & $2 / 3$ & $3 / 4$ \\
6 & & & 120 & $3 / 4$ & $1 / 2$ \\
\hline 7 & & & 60 & $1 / 2$ & $2 / 3$ \\
8 & 0.60 & 0.40 & 90 & $2 / 3$ & $3 / 4$ \\
9 & & & 120 & $3 / 4$ & $1 / 2$ \\
\hline
\end{tabular}

Table 1. Factorial design variables.

\begin{tabular}{|c|c|c|c|c|c|c|c|c|c|c|c|c|c|c|}
\hline \multicolumn{6}{|c|}{ Flow, $\mathrm{Nm}^{3} \cdot \mathrm{min}^{-1}$} & \multicolumn{6}{|c|}{ Radial position, (r/R) } & \multirow{2}{*}{\multicolumn{3}{|c|}{$\begin{array}{c}\text { Angle }^{\circ} \\
-\end{array}$}} \\
\hline & Flow 1 & & & Flow 2 & & $\operatorname{Rac}$ & pos & & $\operatorname{Rac}$ & 1 posi & n 2 & & & \\
\hline 0.80 & 0.70 & 0.60 & 0.20 & 0.30 & 0.40 & $1 / 2$ & $2 / 3$ & $3 / 4$ & $1 / 2$ & $2 / 3$ & $3 / 4$ & 60 & 90 & 120 \\
\hline
\end{tabular}

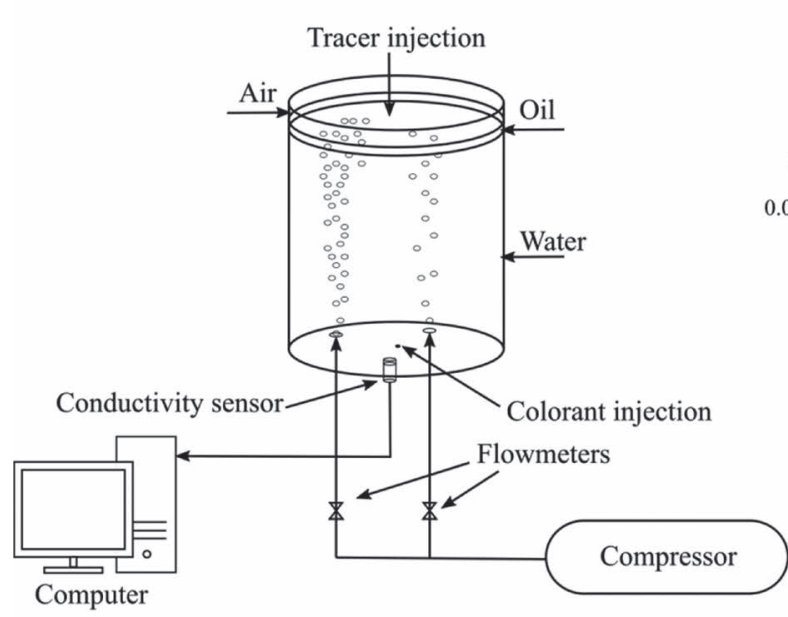

a)

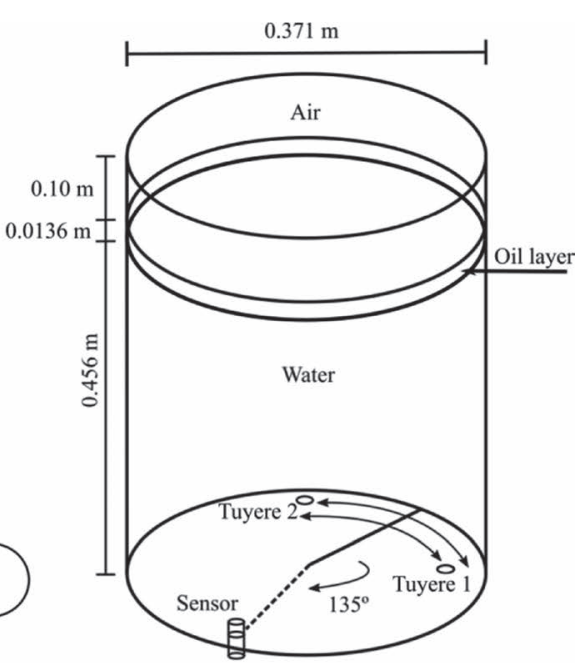

b)

Fig. 2. (a) Experimental setup and (b) ladle scale model. 
the height of liquid, $\mathrm{m} ; \rho_{g}, \rho_{a}, \rho_{w}$ and $\rho_{s}$, are the densities of argon, air, water and steel, $\mathrm{kg} \cdot \mathrm{m}^{-3}$. The degree of mixing at a time $t$, in the water was determined by Eq. (2): ${ }^{29)}$

$$
D_{m i x}^{t}=\frac{C_{t}-C_{i}}{C_{\infty}-C_{i}}
$$

where $C_{i}$, is the initial concentration; $C_{t}$, represents the concentration at time $t$; and $C_{\infty}$ is the final concentration determined by the sensor.

\subsection{Dye Dispersion Technique}

The fluid dynamic structure predicted by multiphasic mathematical modeling was validated by qualitative comparison of case 2 with dye dispersion images in the physical model. The dispersion of the red dye tracer was carried out by injecting $30 \mathrm{~mL}$ of a supersaturated solution through a hole located in the center of the bottom of the ladle, at a rate of $2 \mathrm{~mL} \cdot \mathrm{s}^{-1}$ to avoid modify the fluid dynamic structure of water. The dye was added when the water reached the quasi-stable state, approximately at $15 \mathrm{~s}$ of air injection. Images of the behavior of the dye were captured during the first seconds after injection until water saturation.

\subsection{Multiphasic Mathematical Modeling}

\subsubsection{Ladle Dimensions and Boundary Conditions}

The ladle furnace considered for this study has a capacity of 136 tons, the phases and boundary conditions used in the numerical simulation are shown in Fig. 3(a). The computational mesh used was of 730730 elements. Ansys
Fluent $15.0^{\circledR}$ software was employed to perform the numerical calculation process. Figure 3(b) shows the dimensions and location of the sensors for determining the mixing time in the computational model. For the fluid dynamic analysis two planes were considered: the plane A, passing through the center of the two injection plugs; and the plane B, which is normal to plane A and intersecting it at half the distance between the plugs as shown in the Fig. 3(c). Table 3, lists the properties of the materials used in multiphase mathematical simulation.

\subsubsection{Continuity Equation}

The VOF model can simulate two or more immiscible

Table 3. Materials properties.

\begin{tabular}{cccc}
\hline Material/Interphase & $\begin{array}{c}\text { Density, } \\
\left(\mathrm{kg} \cdot \mathrm{m}^{-3}\right)\end{array}$ & $\begin{array}{c}\text { Viscosity, } \\
\left(\mathrm{kg} \cdot \mathrm{m}^{-1} \cdot \mathrm{s}^{-1}\right)\end{array}$ & $\begin{array}{c}\text { Interphase tensión, } \\
\left(\mathrm{N} \cdot \mathrm{m}^{-1}\right)\end{array}$ \\
\hline Steel & 7020 & 0.006 & - \\
Slag & 3500 & 0.2664 & - \\
Argon & 1.6228 & $2.125 \times 10^{-5}$ & - \\
Air & 1.225 & $1.7894 \times 10^{-5}$ & - \\
Steel-argon & $* *$ & $* *$ & 0.12 \\
Slag-argon & $* *$ & $* *$ & 1.192 \\
Steel-slag & $* *$ & $* *$ & 1.6 \\
Steel-air & $* *$ & $* *$ & 0.58
\end{tabular}

** Calculated from Eq. (6).

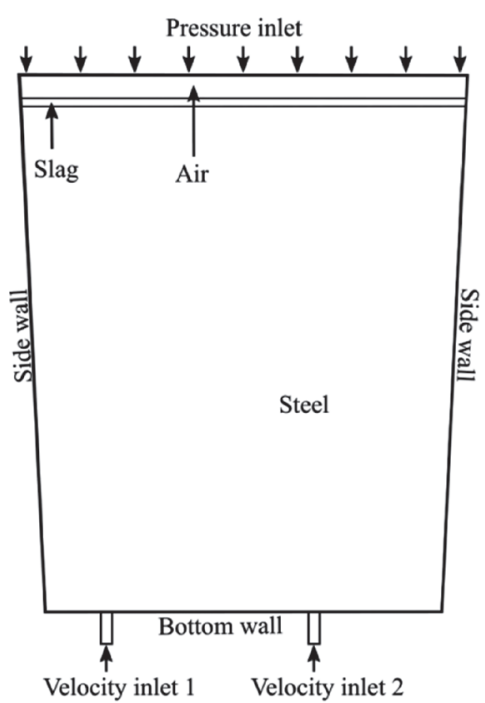

a)

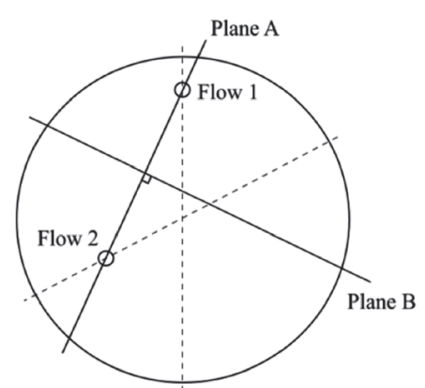

c)

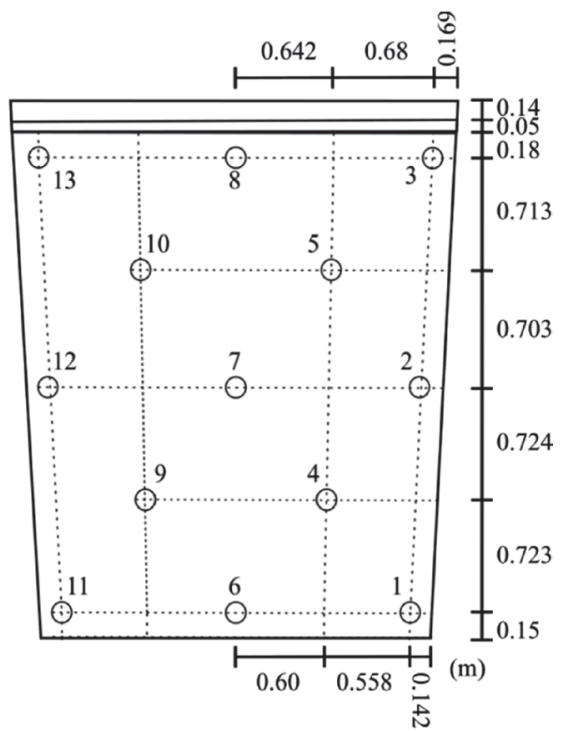

b)

Fig. 3. Computational domain of ladle. a) boundary conditions, b) dimensions and sensors position, c) planes of study. 
fluids by solving a single set of momentum equations and tracking the volume fraction of each of the fluids throughout the domain. A continuity equation has to be solved for the volume fraction of one or more phases. ${ }^{30 \text { ) }}$

$$
\frac{\partial}{\partial t}\left(\alpha_{q} \rho_{q}\right)+\nabla \cdot\left(\alpha_{q} \rho_{q} \vec{v}_{q}\right)=0
$$

where, for phase $q$ : $\rho_{q}$ is the density, $\mathrm{kg} \cdot \mathrm{m}^{-3} ; \alpha_{q}$ is the volumetric fraction within the cell; and $\vec{v}_{q}$ is the velocity $\mathrm{m} \cdot \mathrm{s}^{-1}$. The volumetric fraction is defined according to Eq. (4):

$$
\sum_{q=1}^{n} \alpha_{q}=1
$$

\subsubsection{Equation of Conservation of Momentum}

The balance of the forces involved in the process is based on the solution of a single equation of momentum for all phases Eq. (5) and whose resolution depends on the properties of each phase determined by their volume fraction. ${ }^{30}$ )

$$
\frac{\partial}{\partial t}(\rho \vec{v})+\nabla \cdot(\rho \vec{v} \vec{v})=-\nabla p+\nabla \cdot\left[\mu\left(\nabla \vec{v}+\nabla \vec{v}^{T}\right)\right]+\rho \vec{g} \cdots
$$

where: $\rho$ and $\mu$, are -respectively- the density, $\mathrm{kg} \cdot \mathrm{m}^{-3}$, and viscosity, $\mathrm{Pa} \cdot \mathrm{s}$, of the material as a function of the volume fraction; $\nabla p$, is the variation of the pressure, $\mathrm{Pa}$; and $\vec{g}$, is the gravitational acceleration, $\mathrm{m} \cdot \mathrm{s}^{-2}$. The properties of the mixture (density, viscosity, etc.) are calculated from the volume fraction and properties of each phase $-x_{q}$ - using Eq. (6). ${ }^{30)}$

$$
x=\sum \alpha_{q} x_{q}
$$

\subsubsection{Model of Turbulence k- $\varepsilon$}

Turbulent behavior is simulated using the standard $k-\varepsilon$ model, ${ }^{31)}$ which solves two equations: one for turbulent kinetic energy, $k$, (Eq. (7)), and another for dissipation of turbulent kinetic energy, $\varepsilon$, (Eq. (8)).

$$
\frac{\partial}{\partial t}(\rho k)+\nabla \cdot(\rho k \vec{v})=\nabla \cdot\left[\left(\mu+\frac{\mu_{t}}{\sigma_{k}}\right) \nabla k\right]+G_{k}+G_{b}-\rho \varepsilon
$$

$$
\begin{aligned}
\frac{\partial}{\partial t}(\rho \varepsilon)+\nabla \cdot(\rho \varepsilon \vec{v})= & \nabla \cdot\left[\left(\mu+\frac{\mu_{t}}{\sigma_{\varepsilon}}\right) \nabla \varepsilon\right] \\
& +C_{1 \varepsilon} \frac{\varepsilon}{k}\left(G_{k}+C_{3 \varepsilon} G_{b}\right)-C_{2 \varepsilon} \rho \frac{\varepsilon^{2}}{k}
\end{aligned}
$$

Where $G_{k}$, is the turbulence kinetic energy generation by the average velocity gradient; is the turbulence kinetic energy generation due to buoyancy; $\mu_{t}$, is the turbulent viscosity; $C_{1 \varepsilon}, C_{2 \varepsilon}$ and $C_{3 \varepsilon}$ are constants whose values are 1.44, 1.92 and 1 , respectively; $\sigma_{k}$ and $\sigma_{\varepsilon}$ are the turbulent Prandtl numbers for $k$ and $\varepsilon$, whose values used for these constants are 1.0 and 1.3 , respectively. ${ }^{31)}$

\subsubsection{Species Transport Equation ${ }^{30)}$}

For the tracer dispersion simulation, the species transport model was used, which is solved by Eq. (9),

$$
\frac{\partial}{\partial t}\left(\alpha_{q}^{i} \rho_{q}^{i} Y_{i}^{q}\right)+\nabla \cdot\left(\alpha_{q}^{i} \rho_{q}^{i} \vec{v}_{q}^{i} Y_{i}^{q}\right)=-\nabla \cdot \vec{J}_{i}
$$

where, $\alpha_{q}^{i}, \rho_{q}^{i} \mathrm{y} \vec{v}_{q}^{i}$, represent the volume fraction, density and velocity of the phase $q$ that contains the species $i ; Y_{i}^{q}$ is the mass fraction of the species $i$ contained in phase q; $\vec{J}_{i}$, is the diffusive flux of the species $i$.

\subsection{Determination of Mixing Time for a Multi-sensor System}

The mixing time in the ladle furnace was determined by monitoring the concentration of a tracer substance whose physical properties are equal to those of steel. For this, a methodology was proposed in which the average normalized concentration of the thirteen sensors at a time $t$, is determined by Eq. (10),

$$
\bar{C}_{t}=\frac{1}{\mathrm{k}} \sum_{j=1}^{\mathrm{k}} C_{j}^{t}
$$

where $C_{j}^{t}$, is the concentration of sensor $j$ at time $t ; \mathrm{k}$, is the number of sensors considered. Bulk homogeneity is established when the concentration in all sensors varies less than $5 \%$ with respect to the average concentration, then at a time $t$ the upper $-L_{\text {upper }}^{t}$ - and lower $-L_{\text {lower }}^{t}$ - limits are established according to Eqs. (11) and (12), respectively.

$$
\begin{aligned}
& L_{\text {upper }}^{t}=1.05 \cdot \bar{C}_{t} \\
& L_{\text {lower }}^{t}=0.95 \cdot \bar{C}_{t}
\end{aligned}
$$

The criterion to establish if a sensor is within the 5\% variation with respect to the average concentration is determinated by Eq. (13), there is a degree of mixture of $95 \%$ when the conditions established in Eq. (13) are reached,

$$
\begin{aligned}
& C_{j}^{t}-L_{\text {upper }}^{t} \leq 0 \\
& L_{\text {lower }}^{t}-C_{j}^{t} \leq 0
\end{aligned}
$$

\section{Results and Discussion}

\subsection{Validation of Results}

The validation of the mathematical model was carried out qualitatively and quantitatively using case 2 . The qualitative validation of the fluid dynamic structure was carried out by means of the dispersion of the red dye tracer, in which a plane was selected showing both plumes as illustrated in Fig. 4. Initially the dye ascends due to the drag caused by air plumes, as seen in Fig. 4(a). At point (1) a low speed zone is formed, which is caused by a recirculation as predicted by the mathematical model at point 1 of Fig. 4(e). When the dye reaches the free surface, it is redirected to the wall following the path of the fluid as seen in Fig. 4(b). At the point (2) of Fig. 4(c), a zone of low dye concentration is generated as a result of the downward flow of the recirculation (3) and the upward flow near the plume. This zone corresponds to point 2 of Fig. 4(e). On the other hand, in Fig. 4(d) it is observed that the main recirculation (4) occupies almost the entire volume according to that obtained by the mathematical model, point 4 of Fig. 4(e). From this comparison, it is observed that there is good agreement using both techniques. The quantitative validation of mixing time is shown in Fig. 5. Figure 5(a) illustrates the mixing time obtained by the physical model, where the results of the 5 tests and the average of these are showed. The dispersion 
among the readings at the beginning of the tests is because at these times the concentration gradient is high enough and the data adquisition frecuency is low. However, the experimental error decreases as the homogenization approaches $100 \%$, hence it does not interfere with the result of mixing time, whose value was 35 s. Figure 5(b) shows the variation of the tracer substance (i.e. species) for the 13 sensors of the multiphase mathematical model. Sensors 3, 5 and 8 have the highest values at the start of monitoring because they are located in the tracer injection zone, unlike sensors 1,6 and 11 located at the bottom that indicate low tracer

a)

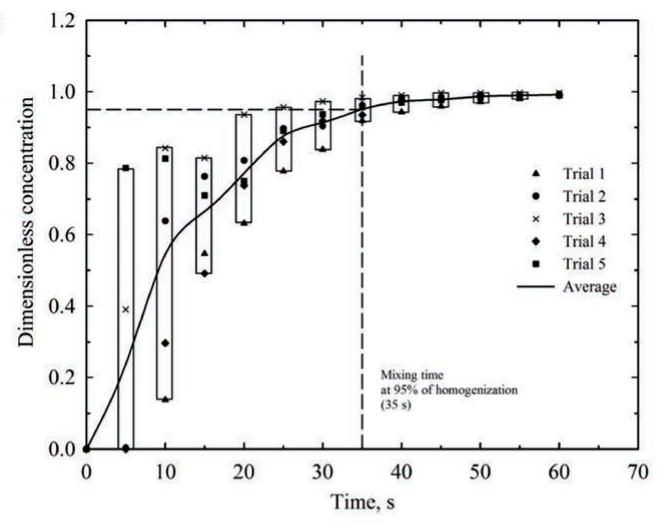

b)

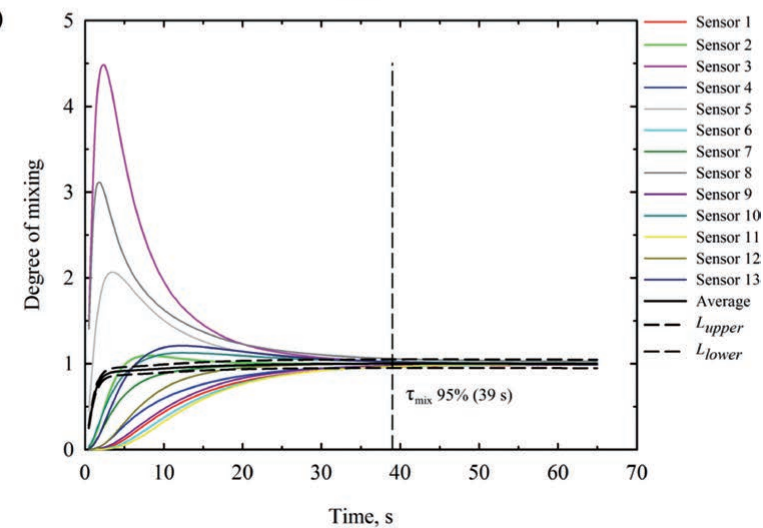

Fig. 5. Mixing time for case 2 obtained from a) experimental and b) mathematical simulation.

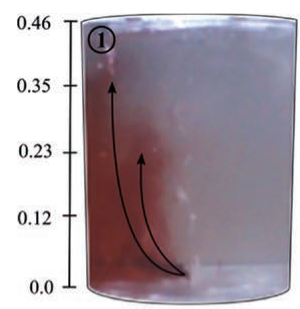

a)

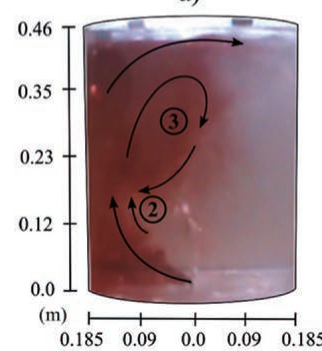

c)

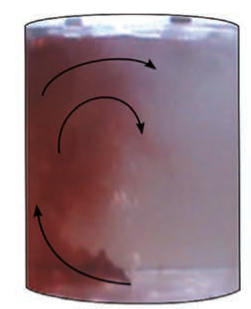

b)

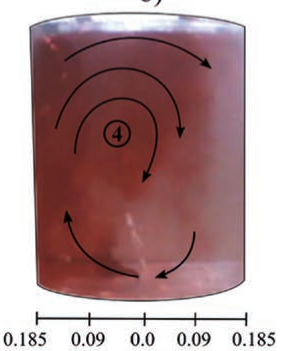

d) values at the beginning. However, towards the end all the values have an asymptotic behavior of $100 \%$ mixing degree. It was found that all sensors vary by less than $5 \%$ of the average at a time of $39 \mathrm{~s}$. According to the results obtained between both techniques, and the great concordance in the mixing time, the mathematical simulation was employed for the rest of the cases.

\subsection{Mixing Time}

A summary of the mixing times obtained by multiphasic mathematical modeling for the 9 proposed cases is shown in Fig. 6. In cases 2 and 8, are obtained the shortest mixing time (39 s); while case 3 reaches $95 \%$ homogeneity at 44.5 s. Figure 7 shows the relevance of each variable on the mixing time, it is observed that the angle between the tuyeres modifies significantly the mixing time. However, mantaining an constant angle of $90^{\circ}$ it does not significantly influence the mixing time; on the contrary, different angles reflect considerable variations for the different flows.

\subsection{Fluidynamics Structure}

For the analysis of the fluid dynamic structure, cases 2, 3,8 and 9 were chosen because they are representative of the mixing time range. Figure 8(a) shows the plane A for

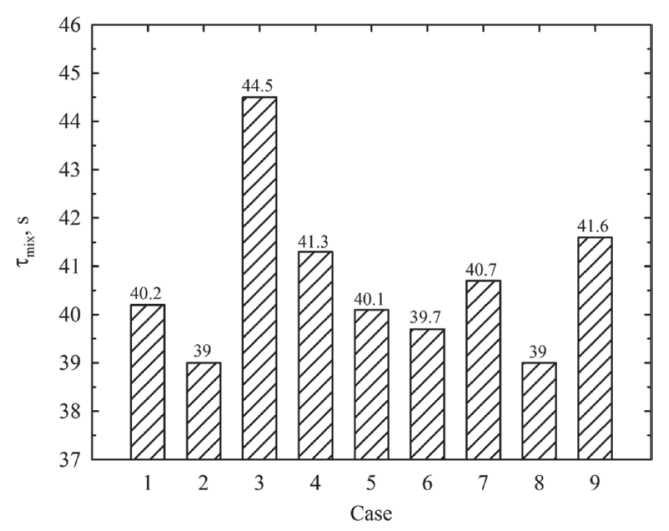

Fig. 6. Mixing time predicted by numerical simulation for the 9 cases.

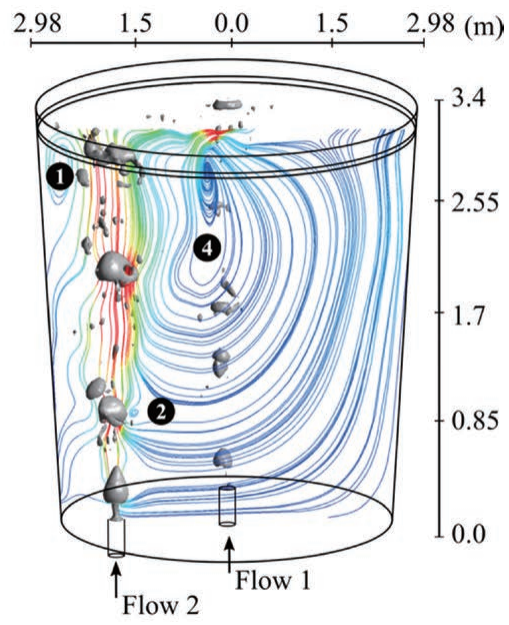

e)

Fig. 4. Dye dispersión at a) $5 \mathrm{~s}$, b) $7 \mathrm{~s}$, c) $9 \mathrm{~s}$, d) $11 \mathrm{~s}$ and e) pathlines predicted by numerical simulation after quasisteady state. 


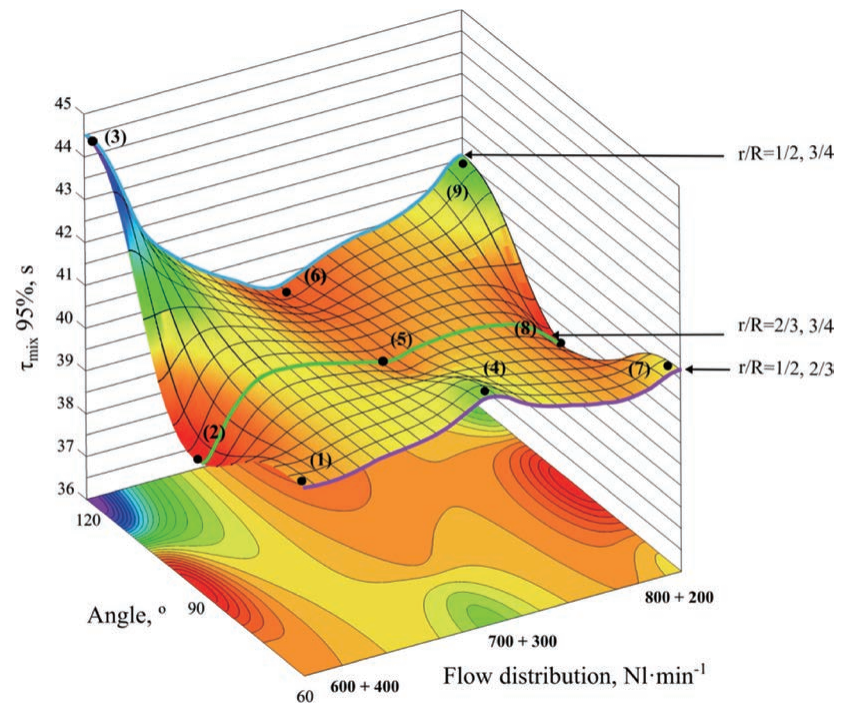

Fig. 7. Effect of the studied variables over mixing time.

case 3 which represents the highest mixing time, where it is observed the plumes interact each other in the upper zone generating a recirculation (1). Other two recirculations -(2) and (3)- are also formed close to the interphase steel-slag between the plumes and the respective sidewall. These recirculations are produced by the drag and the exchange of momentum between the plume and the steel. Finally, the biggest and elongated recirculation (4) is produced close to the sidewall owing to the interaction between it and the right ascendant flow. Figure 8(b) shows plane B for the same case, where there are two major asymmetrical recirculations - (5) and (6) - that produces the wall-type effect where intereact each other. Figure 8(c) shows the plane A for case 9 that computed an intermediate mixing time, different to case 3 in this case there are two recirculations - (7) and (8) - between the plumes which turn in opposite direction. Furthermore, only one elongated recirculacion (9) between the right plume and sidewall close to the slag layer is formed due to a higher velocity plume. At last, recirculation (10) remains similar to that of the case 3. In Fig. 8(d) for plane B, two recirculations placed at two different heights - (11) and (12) - can be seen, which, when interact each other, it generates a virtual plane of wall-type effect as well as case 3. Figure 8(e) that corresponds to plane A for case 8, different to the previous cases, it shows a high symmetry in recirculations distribution, generating two recirculations - (13) and (14)- between the plumes and other two - (15) and (16)- within the plume and sidewalls. The above, because of the low differences in gas flow rates. Figure 8(f) shows the plane B, it can be observed one large recirculation (17) over the whole bulk that compared to previous cases, in this the length of the wall-type effect is diminished as pointed out by (18). According to the results of mixing time, similar to case 8 , case 2 obtained the same mixing time. Both have a very similar radial relationship and angular distance configuration between tuyeres; however, there is a marked difference in the asymmetry of the gas inlet flows for both cases. Therefore, it was considered pertinent to carry out the analysis for case 2 . Figures $8(\mathrm{~g})$ and $8(\mathrm{~h})$, show the fluidynamic structure for planes A and $\mathrm{B}$, respectively. It can be seen that no mayor differences exist between these cases -2 and 8 -. From the results, the

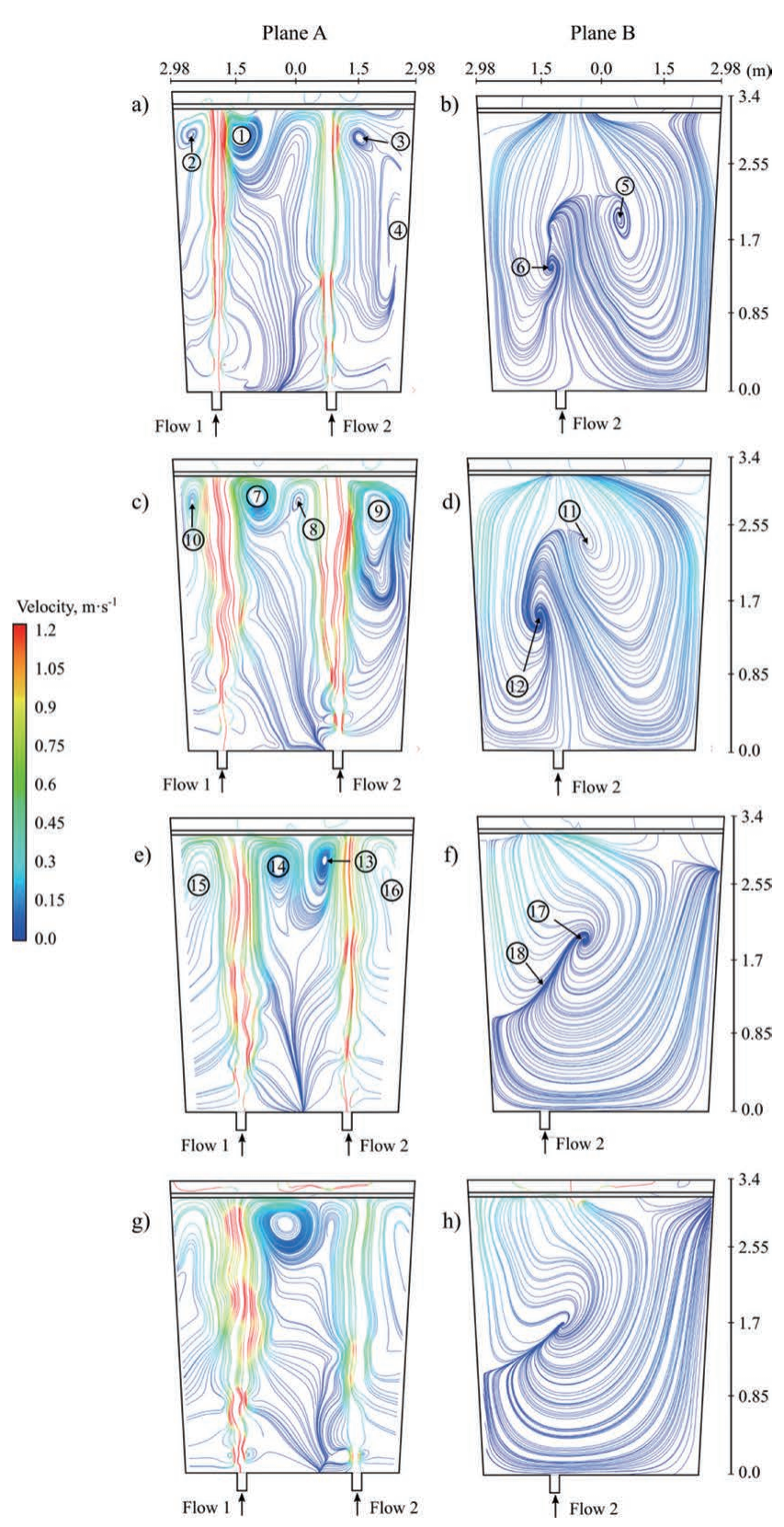

Fig. 8. Fluidynamics structure for planes A and B. a) and b) case 3, c) and d) case 9, e) and f) case 8 and g) and h) case 2 .

differences in fluidynamics structure is the main cause of the variation between mixing times. The occurence of wall-type effect zones increase the mixing time, because they inhibit the homogeneous distribution of the tracer between different regions of the steel. This is consistent with the hypothesis presented by González et al., ${ }^{32)}$ which attributes the increases of mixing time to the formation of a great number of recirculations. Finally, from analysis between case 2 and 8 where the fluid dynamics structure is very similar, allows to explain why in industrial practice the homogenization times are preserved independently if there is a partial blockage in one of the tuyeres, while maintaining the global flow of argon gas constant.

\section{Conclusions}

According to the results obtained in the multiphase mathematical simulation of the stirring of the ladle, can be 
concluded the following:

(1) It was demonstrated that the use of mathematical simulation is a tool that allows the analysis of processes when the results are validated by experimental techniques. The above, as was demonstrated using dye tracer dispertion and mixing times techniques employing a physical scale model.

(2) The effect of the angle of separation between the injection plugs has a greater influence on the decrease in mixing time than the distribution of the injected gas flow, corroborating what was established by previous studies. ${ }^{33)}$

(3) A fluid dynamics structure that contains greather large recirculations and virtual planes of wall-type effect influences the steel flow direction, inhibiting the homogeneous distribution of the tracer and increasing the mixing time. On the other hand, it is recommended that a single large recirculation be generated in the bulk as previously reported. ${ }^{11,32)}$

(4) In this study, it was found that while maintaining an angle of $90^{\circ}$ and radial positions of $2 / 3$ and $3 / 4$ the mixing times were shorter, regardless of the asymmetric flow distribution.

\section{Acknowledgments}

The authors want to acknowledge to the TecNM-ITM, CÁTEDRAS-CONACyT, UMSNH-FIM, CONACyT and SNI for the permanent support to the academic groups of Modeling of Metallurgical Processes and Thermofluids.

\section{Nomenclature}

\section{Symbol Descripción}

$C_{1 \varepsilon}, C_{2 \varepsilon}, C_{3 \varepsilon}:$ Turbulence model constants.

$C_{i}, C_{\infty}, C_{t}$ : Initial, final and at time $t$ concentrations

$\bar{C}_{t}$ : Average mixing degree at time $t$, Adimensional

$C_{j}^{t}$ : Mixing degree of sensor $j$ at time $t$, Adimensional

$D_{\text {mix }}^{t}$ : Mixing degree, Adimensional

$g$ : Gravitational acceleration, $\mathrm{m} \cdot \mathrm{s}^{-2}$

$G_{b}$ : Turbulence production due bouyancy

$G_{k}$ : Turbulence production due mean velocity

$H$ : Injection deep, $\mathrm{m}$

$J_{i}$ : Diffusion flux of especie $i, \mathrm{~kg} \cdot \mathrm{m}^{-2} \cdot \mathrm{s}^{-1}$

$j$ : Sensor number $j$

$k$ : Turbulent kinetic energy, $\mathrm{J} \cdot \mathrm{kg}^{-1}$

$\mathrm{k}$ : Total number of sensors

$L_{\text {lower }}^{t}$ : Lower limit of mixing variation

$L_{\text {lower }}^{t}:$ Upper limit of mixing variation

$p$ : Pressure, $\mathrm{Pa}$

Q: Gas flow, $\mathrm{Nm}^{3} \cdot \mathrm{min}^{-1}$

$q$ : Phase $q$

$\mathrm{r}$ : Radial distance of tuyere, $\mathrm{m}$

$\mathrm{R}$ : Radius of ladle, $\mathrm{m}$

$v$ : Velocity, $\mathrm{m} \cdot \mathrm{s}^{-1}$

$x$ : Propierty of system used in VOF model

$Y_{i}$ : Mass fraction of especie $i$, Adimensional

Greek symbols

$\alpha$ : Volume fraction, Adimensional

$\varepsilon$ : Rate of dissipation of turbulen kinetic energy

$\theta$ : Angle,

$\mu$ : Viscosity, $\mathrm{Pa} \cdot \mathrm{s}$

$\mu_{t}$ : Turbulent viscosity, $\mathrm{Pa} \cdot \mathrm{s}$

$\rho$ : Density, $\mathrm{kg} \cdot \mathrm{m}^{-3}$

$\tau_{\text {mix }}:$ Mixing time, Adimensional

\section{REFERENCES}

1) D. Geng, H. Lei and J. He: Int. J. Miner. Metall. Mater., 17 (2010), 709. https://doi.org/10.1007/s12613-010-0378-5

2) M. Zhu, T. Inomoto, I. Sawada and T. Hsiao: ISIJ Int., 35 (1995), 472. https://doi.org/10.2355/isijinternational.35.472

3) S. Ganguly, A. Kumar and S. Chakraborty: ISIJ Int., 44 (2004), 1960. https://doi.org/10.2355/isijinternational.44.1960

4) M. Andersson, L. Jonsson and P. Jönsson: ISIJ Int., 40 (2000), 1080. https://doi.org/10.2355/isijinternational.40.1080

5) S. Joo and R. Guthrie: Metall. Trans. B, 23 (1992), 765. https://doi. org/10.1007/BF02656455

6) M. Madan, D. Satish and D. Mazumdar: ISIJ Int., 45 (2005), 677. https://doi.org/10.2355/isijinternational.45.677

7) J. Mandal, S. Patil, M. Madan and D. Mazumdar: Metall. Mater. Trans. B, 36 (2005), 479. https://doi.org/10.1007/s11663-005-0039-7

8) K. Krishnakumar and N. Ballal: ISIJ Int., 39 (1999), 1120. https:// doi.org/10.2355/isijinternational.39.1120

9) A. Conejo, S. Kitamura, N. Maruoka and S. Kim: Metall. Mater. Trans. B, 44 (2013), 914. https://doi.org/10.1007/s11663-013-9829-5

10) K. Michalek, K. Gryc and J. Morávka: Metalurgija, 48 (2009), 219. https://hrcak.srce.hr/38684

11) C. A. Llanos, S. Garcia-Hernandez, J. A. Ramos-Banderas, J. de J. Barreto and G. Solorio-Diaz: ISIJ Int., 50 (2010), 396. https://doi. org/10.2355/isijinternational.50.396

12) J. Pieprzyca, Z. Kudlinski, K. Michalek, K. Gryc and M. Tkadleckova: J. Achiev. Mater. Manuf. Eng., 55 (2012), 573.

13) J. Mietz and F. Oeters: Steel Res., 60 (1989), 387. https://doi. org/10.1002/srin.198901673

14) H. Liu, Z. Qi and M. Xu: Steel Res. Int., 82 (2011), 440. https://doi. org/10.1002/srin.201000164

15) T. Haiyan, G. Xiaochen, W. Guanghui and W. Yong: ISIJ Int., 56 (2016), 2161. https://doi.org/10.2355/isijinternational. ISIJINT-2016-360

16) K. Nakanishi, T. Fujii and J. Szekely: Ironmaking Steelmaking, 2 (1975), 193.

17) D. Mazumdar and R. Guthrie: Metall. Trans. B, 17 (1986), 725. https://doi.org/10.1007/BF02657134

18) D. Mazumdar and R. Guthrie: Iron Steelmaker, 26 (1999), 89.

19) O. Haida, T. Emi, S. Yamada and F. Sudo: Proc. 2nd Int. Conf. on Injection Metallurgy (Scaninject II), MEFOS, Luleå, (1980), 15.

20) S. Patil, D. Satish, M. Peranandhanathan and D. Mazumdar: ISIJ Int., 50 (2010), 1117. https://doi.org/10.2355/isijinternational.50.1117

$21)$ D. Mazumdar and J. Evans: ISIJ Int., 44 (2004), 447. https://doi. org/10.2355/isijinternational.44.447

22) D. Mazumdar, S. Das and S. Bajpayee: ISIJ Int., 37 (1997), 194. https://doi.org/10.2355/isijinternational.37.194

23) S. W. Petrus Cloete: Master thesis, Stellenbosch University, South-Africa, (2008), 1, https://www.researchgate.net/ publication/44138652_A_mathematical_modelling_study_of_fluid_ flow and mixing in gas stirred ladles, (accessed $2008-1 \overline{2}-1 \overline{5}$ ).

24) L. E. Jardón-Pérez, D. R. González-Morales, G. Trápaga, C. González-Rivera and M. A. Ramírez-Argáez: Metals, 9 (2019), 555. https://doi.org/10.3390/met9050555

25) D. C. Montgomery: Design and Analysis of Experiments, John Wiley \& Sons, Inc., Hoboken, NJ, (2013), 410.

26) A. Jauhiainen, L. Jonsson and D. Sheng: Scand. J. Metall., 30 (2001), 242. https://doi.org/10.1034/j.1600-0692.2001.300408.x

27) K. Michalek, K. Gryc and J.Morávka: Metalurgija, 48 (2009), 215. https://hrcak.srce.hr/38683

28) K. Krishnapisharody and G. Irons: Metall. Mater. Trans. B, 44 (2013), 1486. https://doi.org/10.1007/s11663-013-9943-4

29) G. G. Krishna Murthy and J. F. Elliot: ISIJ Int., 32 (1992), 190. https://doi.org/10.2355/isijinternational.32.190

30) ANSYS Fluent Theory Guide, ANSYS, Inc., Canonsburg, (2013).

31) B. Launder and D. Spalding: Lectures in Mathematical Models of Turbulence, Academic Press, London, (1972), 1.

32) R. González-Bernal, G. Solorio-Diaz, A. Ramos-Banderas, E. Torres-Alonso, C. A. Hernández-Bocanegra and R. Zenit: Steel Res. Int., 89 (2018), 1700281. https://doi.org/10.1002/srin.201700281

33) W. Lou and M. Zhu: ISIJ Int., 54 (2014), 9. https://doi.org/10.2355/ isijinternational.54.9 